was $12,3( \pm 4,5)$ and the $73 \%$ were female subjects. In 6 months the burden to society to care for an OA patient was around 1.993 Euro (year 2000 value). Almost 33\% of this cost was represented by direct costs and about $67 \%$ by indirect costs. In general, the most important component of cost was informal care, followed by productivity losses and direct medical cost. Statistical analysis: The total cost was significantly associated with disease severity ( $\mathrm{p}<0,001$ ), increasing with increasing severity as measured through LI quartiles.

Conclusion From our results, it appears that interventions reducing LI score are likely to reduce the amount of resources needed to care for OA patients.

\section{SAT0239 THE RESPONSIVENESS OF HEALTH STATUS MASURES AND UTILITY-BASED METHODS IN PATIENTS WITH RHEUMATOID ARTHRITIS}

${ }^{1} \mathrm{~F}$ Salaffi, ${ }^{1} \mathrm{~A}$ Stancati, ${ }^{2} \mathrm{M}$ Carotti, ${ }^{1} \mathrm{~W}$ Grassi. ${ }^{1}$ Department of Rheumatology, University of Ancona, Jesi, Italy; ${ }^{2}$ Department of Radiology, University of Ancona, Ancona, Italy

10.1136/annrheumdis-2001.875

\section{Background}

Objectives To compare the responsiveness of disease-specific (Arthritis Impact Measurement Scale 2, AIMS2), ${ }^{1,2}$ generic (Medical Outcome Study Short Form Health Survey, SF-36) ${ }^{3}$ and preference-based instruments (rating scale, RS and time trade off, TTO $)^{4}$ to changes in particular status and perceived health in patients with rheumatoid arthritis (RA).

Methods Seventy-eight consecutive patients with RA, attending the care facilities of the Department of Rheumatology of Ancona, were recruited to the longitudinal study. Changes in global disease activity assessed by using the EULAR criteria were used as external indicators of improvement/response. In order to assess the responsiveness three strategies were used: 1) effect size (ES, mean change/standard deviation of baseline values); 2) standardised response mean (SRM, mean change/standard deviation of change in stable subjects); and 3) receiver operating characteristic method.

Results There were 55 women and 23 men with a mean age of 56 years (range 19-78 years) and arthritis duration of 7.1 years (range 6 months-24 years). By using a 3 category EULAR criteria for improvement/response, $21(27 \%)$ patients reported a good improvement, $23(29,5 \%)$ moderate improvement, and 34 $(43,5 \%)$ no changes in their arthritis over 12 months. The mean change score in generic and specific health status instruments and in utility measures, were significantly related to response category. There were no significant differences in responsiveness between SF-36 and AIMS2 in patients with RA when using changes in global disease activity as external indicator. The pain subscales were most sensitive to measure change over time, followed by physical function and psychosocial subscales. For the utility measurement, RS scores were found to be more responsive in detecting significant changes in preferences than TTO scores.

Conclusion The results suggest that both the SF-36 and AIMS2 may prove suitable for the assessment of health perception outcomes in RA clinical trials. Concerning the patient utilities the RS method appeared to be more responsive than TTO method. New strategies for assessing sensitivity to small changes should be developed and applied to health status and utility measures.

\section{REFERENCES}

1 Meenan RF, Mason JK, Anderson JJ, Guccione AA, Kazis LE. AIMS2. The content and properties of a revised and expanded arthritis impact measurement scales health status questionnaire. Arthritis Rheum. 1992;35:1-10

2 Salaffi F, Piva S, Barreca C, on behalf of Gonarthrosis and Quality of Life (GOQUOLA) Study Group. Validation of an italian version of the Arthritis Impact Measurement Scales 2 (ITALIAN AIMS2) for patients with osteoarthiritis of the knee. Rheumatology 2000;39:720-6

3 Ware JE Jr, Sherbourne CD. The MOS 36-item short form health survey (SF-36). 1 Conceptual frame-work and item selection. Med Care 1992;30:473-81

4 Torrance G. Utility approach to measuring health related quality of life. J Chronic Dis. 1987;40:593-600

\section{SAT0240 COST EFFECTIVENESS OF CYCLOSPORINE (SANDIMMUNNEORAL ${ }^{\oplus}$ ) TREATMENT IN EARLY SEVERE RHEUMATOID ARTHRITIS: THE GRISAR STUDY}

${ }^{1}$ LG Mantovani, ${ }^{1} \mathrm{~A}$ Belisari, ${ }^{1} \mathrm{M}$ Pisani, ${ }^{2} \mathrm{G}$ Pasero, ${ }^{3} \mathrm{E}$ Marubini, ${ }^{4} \mathrm{~F}$ Priolo, ${ }^{5} \mathrm{R}$ Ferrara, $\mathrm{O}$ Della Casa Alberighi ${ }^{6} .{ }^{1}$ Center of Pharmacoeconomics; ${ }^{2}$ Institute of Rheumatology, University of Pisa, Pisa; ${ }^{3}$ Institute of Medical Statistics and Biometry, University of Milan, Milan; ${ }^{4}$ Institute of Radiology, Catholic University, Rome; ${ }^{5}$ Medical Department, Novartis Farma, Origgio, Italy; ${ }^{6}$ Clinical Research and Development, Novartis Pharma, Basel, Switzerland

\subsection{6/annrheumdis-2001.876}

Background Rheumatoid Arthritis (RA) is a chronic, degenerative, disabling and costly disease, particularly in its early form. There is evidence that cyclosporine A (CsA) is a disease modifying antirheumatic drug (DMARD) and is effective in slowing down the joint damage progression of early RA.

Objectives To assess the economic profile of CsA.

Methods TECHNIQUE: Incremental cost effectiveness analysis (CEA). PATIENTS AND DATA: collected from the GRISAR study, a multicenter, prospective, long-term, open-label with a blinded radiological end-point, randomised study of CsA vs conventional DMARDs. ALTERNATIVES: CsA vs conventional DMARDs. PERSPECTIVE: Italian National Health Service. COSTS: direct healthcare costs (drugs, diagnostics, hospitalisations for serious a dverse events -SAEs-) expressed in Euro 2000. EFFECTS: progression in the eroded joint count (PEJC) according to the Larsen-Dale method and reduction in working capacity due to RA. OTUCOME: Incremental cost effectiveness ratio $[$ ICERpejc $=($ Ccsa-Cdmards $) /($ PEJC csa-PEJC dmards $)]$.

Results 248 early severe RA patients (F/M 196/52; mean age $48.7+11.9$ yrs) were considered in this analysis. The mean duration of f-up was 3.9 years. Compared to conventional DMARDs, CsA patients showed higher costs for drugs (Euro 12340 vs $1300, \mathrm{p}<0.05$ ), SAE and diagnostics (Euro 2540 vs $2430, \mathrm{P}=$ $\mathrm{NS}$ ), and total cost (Euro 14880 vs $3730, \mathrm{p}<0.05)$. The progression of RA measured through PEJC was slower in CsA patients compared to conventional DMARDs (1.9 vs 3.2, p < $0.05)$, resulting in an ICER of Euro 8,570 per erosion avoided. Compared to conventinal DMARDs, less patients in the CsA group stopped working because of RA $(2.7 \%$ compared to 7.8\%).

Conclusion This is one of the first prospective CEAs based on a prospective, long-term, randomised clinical trial with a pragmatic design in early RA. Our estimates show that CsA incremental effectiveness is achieved at a reasonable incremental cost. When considered in the perspective of early severe RA, CsA has a favourable pharmacoeconomic profile since CsA. 